\section{Does the knowledge of emergency contraception affect its use among high school adolescents?}

\author{
O conhecimento da contracepção de emergência \\ afeta seu uso entre adolescentes do Ensino \\ Médio do Brasil?
}

¿El conocimiento de la contracepción de emergencia afecta a su uso entre adolescentes de enseñanza media en Brasil?

\begin{abstract}
This study aimed to test how knowledge on emergency contraception (according to age at sexual initiation, type of school, and knowing someone that has already used emergency contraception) influences the method's use. This was a cross-sectional study in a probabilistic sample of students 15-19 years of age enrolled in public and private middle schools in a medium-sized city in Southeast Brazil $(n=307)$. Data were collected in 2011 using a self-administered questionnaire. A structural equations model was used for the data analysis. Considering age at sexual initiation and type of school, knowledge of emergency contraception was not associated with its use, but knowing someone that had used the method showed a significant mean effect on use of emergency contraception. Peer group conversations on emergency contraception appear to have greater influence on use of the method than knowledge itself, economic status, or sexual experience.
\end{abstract}

Postcoital Contraception; Sexual and Reproductive Health;

Adolescent Health
Christiane Borges do Nascimento Chofakian 1 Ana Luiza Vilela Borges 1 Ana Paula Sayuri Sato 2 Gizelton Pereira Alencar ${ }^{2}$ Osmara Alves dos Santos 1 Elizabeth Fujimori 1

\author{
Correspondence \\ C. B. N. Chofakian \\ Escola de Enfermagem, \\ Universidade de São Paulo. \\ Av. Dr. Enéas de Carvalho \\ Aguiar 419, São Paulo, SP \\ 05403-000, Brasil. \\ christianeborges@gmail.com
}




\section{Introduction}

The World Health Organization defines emergency contraception (EC) as modern contraceptive methods that can prevent pregnancy after intercourse. Its use is recommended for any woman of reproductive age, including adolescents, after unprotected intercourse, contraceptive failures or incorrect use, or in cases of sexual assault 1 . Adolescents are an important target group for improving access to all forms of contraceptives, including EC, given that the onset of sexual life generally occurs during that period in the lifespan 2 and that they use contraception for relatively short periods of time, with a high frequency of discontinuities and failures 3 .

The prevalence of EC use among adolescents differs widely due to a very different combination of policies, access and emergency contraceptive methods available in each setting, especially when focusing on young women. Studies have shown that adolescent life-time EC pill use varies across countries - 9\% in Finland $4 ; 14 \%$ in the United States 5; $16 \%$ in Mexico 6; $20 \%$ in Switzerland 7; 28\% in Sweden 8; and 44\% in China $9-$ and across regions in the same country (from $13 \%$ to $32 \%$ in Brazil) 10 . These variations can reflect differences in costs and provider attitudes 11; however, many individual aspects can also influence its use, such as dating, not living in a nuclear family, poor social conditions, and smoking 4,12 .

In Brazil, EC is used by those adolescents who have more control of their reproductive life/behavior, for instance, those who have never been pregnant 10 or are more sexually experienced and have heard about positive experiences regarding the use of EC from their peers 13 . Although $69 \%$ of Brazilian 15-19 year-old girls reported they had already heard of EC 10, the extent to which their knowledge about the method (e.g. mechanism of action, dosage, indications of use) influences its use is unknown. Studies have shown contradictory results regarding the relationship between knowledge of EC and its use 11,14.

Brazil shows peculiar trends in adolescent reproductive behavior, since a high prevalence (73.4\%) 10 in the use of modern methods (mainly condoms and oral pill) coexists with a high prevalence of unwanted and mistimed pregnancies (54.7\%) 15 , confirming contraception discontinuities and failures. Considering that EC is recommended exactly in these situations, our overall aim was to investigate the determinants of its use among adolescents. Our specific aim was to test how the knowledge of EC influences the use of EC among adolescent high school students, accounting for the influence of the age of sexual initiation, type of school and knowledge of someone who has used EC.

\section{Materials and methods}

\section{Study design}

Data were obtained from a broader cross-sectional study conducted in 2011, which had as its aim to assess EC use and knowledge among high school adolescent students in an urban mediumsized city in the state of São Paulo, in the Southeastern region of Brazil.

For the broader study, we interviewed a probabilistic sample of 803 adolescents. Adolescents of both sexes were selected using a two-stage sampling: we first stratified by type of school (public and private school) and then we performed a systematic sampling of classes. The classes were listed separated into public and private schools using first the name of the school in alphabetical order, and then classes by grade in ascending order. The first class was selected at random and the rest according to a predetermined pattern, calculated based on the number of classes required for each type of school. All students attending the selected class were invited to take part in the study one day before the interview date, providing the time to ask for their parents' written consent to participate in the study, a prerogative of the Ethics Research Committee of the University of São Paulo School of Nursing, which approved this study. There were no refusals.

To match the purpose of this study, we considered only the students who had had at least one episode of sexual intercourse, were single and reported having heard about EC. These inclusion criteria generated a subsample and reduced the number of individuals to 307 . We considered this subsample size to be sufficient to respond to the scientific question, given the number of estimated parameters 16,17.

A self-administered questionnaire based on previous studies was prepared 13,18 . This questionnaire was pre-coded and pre-tested with students from schools not selected to take part in the survey. Variables used for this analysis were: use of EC (no/yes), type of school (public/private), age (years), gender (male/female), current dating (no/yes), age of sexual initiation (years), knowledge of someone who had already used EC (no/yes), and ten specific items to measure EC knowledge in which the options were "true", "false" or "don't know" 19: QA - EC should be used before intercourse; QB - EC prevents sexually transmitted diseases (STDs); QC - if vomiting occurs within 2 hours after ingestion of EC, the 
dose should be repeated; QD - EC is more effective than other contraceptives (such as condoms, pill, IUD); QE - EC is to be used within 5 days after unprotected intercourse; QF - EC can be used once a month; QG - EC is abortive; QH - EC should be used only during fertile period; QI - EC replaces the regular oral pill; QJ - when using EC, one is protected from getting pregnant until the next period. The answers were divided into two groups: correct answer, corresponding to the students who answered with the correct option; and incorrect answer, corresponding to the students who either answered with the wrong option or reported not knowing how to answer the item.

\section{Theoretical model}

Figure 1 shows the theoretical model tested with the structured equation model (SEM). The dependent variable was the use of EC (observational data). The knowledge of EC was a latent variable not directly observed. Other observed explanatory variables were the age of sexual initiation, type of school and knowledge of someone who had already used EC. The latent variable and observed variables are represented by ellipse and rectangles, respectively.
Direct effects were estimated. The hypothesis according to this model was that the knowledge of EC, adjusted by the knowledge of someone who had already used EC, type of school and age at sexual initiation, exerts a direct effect on the use of EC. Indirect effects on the use of EC were also estimated: type of school and knowledge of EC on the use of EC; type of school and age of sexual initiation on the use of EC; knowledge of someone who had already used EC and age of sexual initiation on the use of EC; knowledge of someone who had already used EC and knowledge of EC on the use of EC; knowledge of someone who had already used EC and age of sexual initiation and knowledge of EC on use the of EC; and age of sexual initiation and knowledge of EC on the use of EC.

In addition, other effects were estimated: knowledge of someone who had already used EC, age of sexual initiation and type of school on the knowledge of EC; type of school on the age of sexual initiation; and knowledge of someone who had already used EC on the age of sexual initiation.

Figure 1

Theoretical model tested for emergency contraception (EC) use among high school adolescent students. Brazil, 2011.

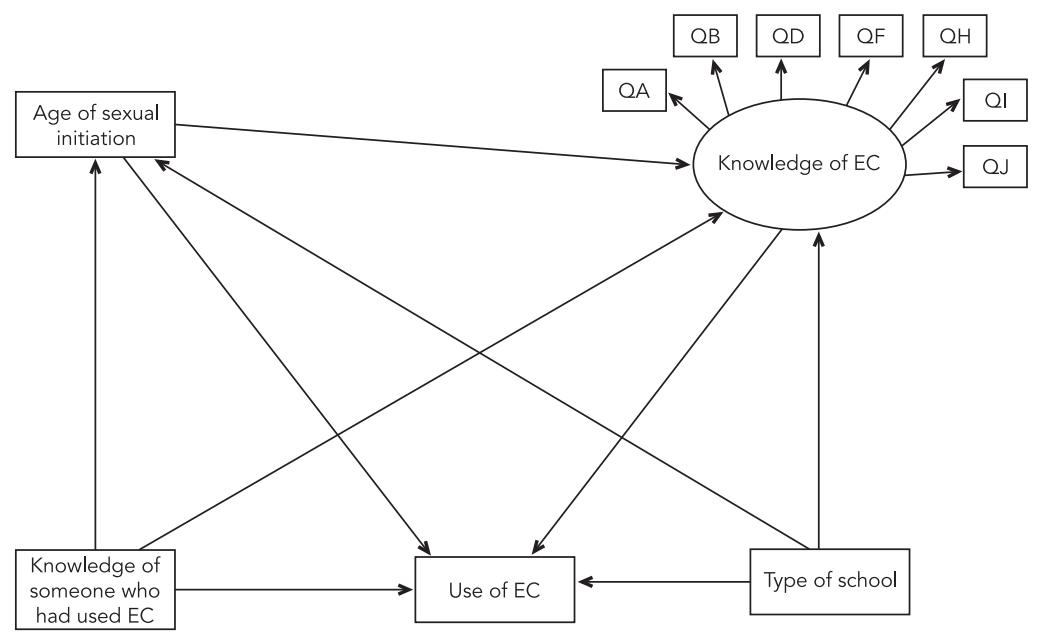

QA: EC should be used before intercourse; QB: EC prevents STDs; QD: EC is more effective tham other contraceptives (such as condoms, pill, IUD); QF: EC can be used once a month; $\mathrm{QH}$ : EC should be used only during fertile period; QI: EC replaces the regular oral pill; QJ: when using EC, once is protected from getting pregnancy until the next period. 


\section{Statistical analysis}

All data analysis was performed using post-stratified sample weight, as this is a complex sample 20. Structural equation modeling was used for the data analysis in Mplus 5.01 (Muthén \& Muthén, Los Angeles, United States).

First, a confirmatory factor analysis (measurement model) using the maximum likelihood robust (MLR) estimator was conducted to indicate whether the observed variables QA-QJ were indicators for the latent variable (knowledge of EC). A good latent variable presents convergent validity, showing that its indicators measure the same construct, as measured by the loads of the indicators (factor loadings) that should be high (> $0.40) 21$. In addition, there should be discriminant validity, i.e., the correlations between indicators should not be excessively high ( $>0.85$ ), since each indicator should measure a distinct aspect of the construct 16 .

A structural equation model using the MLR estimator was conducted to analyze the structural relationships, corresponding to associations between variables. The use of the MLR estimator and the presence of a categorical outcome imply a logistic regression in the regression part of the SEM which allows for the calculation of oddsratios. The standardized coefficients (SC) were interpreted accordingly 22 , where an SC close to 0.10 indicates a small effect, an SC close to 0.30 indicates a medium effect, and SC $>0.50$ indicates a strong effect. In addition, we calculated the odds ratio (OR) for the variables that supposedly exert a direct effect on the dependent variable (use of EC).
The following measures were used as fit indices of the model: chi-square test of model fit, which indicates discrepancy between the sample and fitted covariance matrices (reference value $>0.05$ ); Comparative Fit Index (CFI), which assumes that all latent variables are uncorrelated (null/independence model) and compares the sample covariance matrix with this null model. Values of 0.95 or greater are desirable as this indicates that the hypothesized model produces $95 \%$ or more of the covariation in the data (reference value > 0.95); the Tucker Lewis Index (TLI), in which values higher than 0.95 indicate a good fit (reference value > 0.95); Root Mean Square Error of Approximation (RMSEA), which is a measure of lack of fit per degrees of freedom, controlling for sample size (reference value $<0.05$ ) 23,24 . The significance threshold adopted was $5 \%(\mathrm{p}<0.05)$.

\section{Results}

\section{Descriptive analysis}

Table 1 shows the descriptive analysis of the sample. Half of the adolescents were female (55.1\%). Almost $58 \%$ of the subsample adolescents reported having already used EC. Three-quarters knew someone who had already used EC at least once in the lifetime (76.3\%), and 59.3\% had initiated sexual activity at the age of 15 or older. Seven out of the ten items used to measure the knowledge around EC presented more incorrect answers than correct ones.

Table 1

Number and proportion of adolescents according to sociodemographic variables, sexual and contraceptive behaviors, and knowledge about emergency contraception. Brazil, 2011

\begin{tabular}{|c|c|c|}
\hline Variables & $\mathrm{n}$ & $\%$ \\
\hline \multicolumn{3}{|l|}{ Gender } \\
\hline Male & 138 & 44.9 \\
\hline Female & 169 & 55.1 \\
\hline \multicolumn{3}{|l|}{ Age (years) } \\
\hline 15-16 & 171 & 55.7 \\
\hline $17-19$ & 136 & 44.3 \\
\hline \multicolumn{3}{|c|}{ Type of school } \\
\hline Public & 236 & 76.9 \\
\hline Private & 71 & 23.1 \\
\hline
\end{tabular}

(continues) 
Table 1 (continued)

\begin{tabular}{|c|c|c|}
\hline Variables & $\mathrm{n}$ & $\%$ \\
\hline \multicolumn{3}{|l|}{ Currently dating } \\
\hline No & 159 & 51.6 \\
\hline Yes & 148 & 48.4 \\
\hline \multicolumn{3}{|c|}{ Age of sexual initiation (years) } \\
\hline$\leq 14$ & 125 & 40.7 \\
\hline$\geq 15$ & 182 & 59.3 \\
\hline \multicolumn{3}{|c|}{ Knowledge of someone who had already used EC } \\
\hline No & 73 & 23.7 \\
\hline Yes & 234 & 76.3 \\
\hline \multicolumn{3}{|l|}{ Knowledge of EC } \\
\hline \multicolumn{3}{|c|}{ QA: EC should be used before intercourse } \\
\hline Correct answer & 256 & 83.5 \\
\hline Incorrect answer & 51 & 16.5 \\
\hline \multicolumn{3}{|c|}{ QB: EC prevents STDs } \\
\hline Correct answer & 246 & 80.3 \\
\hline Incorrect answer & 61 & 19.7 \\
\hline \multicolumn{3}{|c|}{ QC: If vomiting occurs within 2 hours after ingestion of EC, the dose should be repeated } \\
\hline Correct answer & 68 & 22.1 \\
\hline Incorrect answer & 239 & 77.9 \\
\hline \multicolumn{3}{|c|}{ QD: EC is more effective than other contraceptives (such as condoms, pill, IUD) } \\
\hline Correct answer & 173 & 56.4 \\
\hline Incorrect answer & 134 & 43.6 \\
\hline \multicolumn{3}{|c|}{ QE: EC is to be used within 5 days after unprotected intercourse } \\
\hline Correct answer & 74 & 24.2 \\
\hline Incorrect answer & 233 & 75.8 \\
\hline \multicolumn{3}{|c|}{ QF: EC can be used once a month } \\
\hline Correct answer & 113 & 36.7 \\
\hline Incorrect answer & 194 & 63.3 \\
\hline \multicolumn{3}{|l|}{ QG: EC is abortive } \\
\hline Correct answer & 92 & 29.9 \\
\hline Incorrect answer & 215 & 70.1 \\
\hline \multicolumn{3}{|c|}{ QH: EC should be used only during fertile period } \\
\hline Correct answer & 137 & 44.5 \\
\hline Incorrect answer & 170 & 55.5 \\
\hline \multicolumn{3}{|c|}{ Ql: EC replaces the regular oral pill } \\
\hline Correct answer & 131 & 42.7 \\
\hline Incorrect answer & 176 & 57.3 \\
\hline \multicolumn{3}{|c|}{ QJ: When using EC, one is protected from getting pregnant until the next period } \\
\hline Correct answer & 101 & 33.0 \\
\hline Incorrect answer & 206 & 67.0 \\
\hline \multicolumn{3}{|l|}{ Previous EC use } \\
\hline No & 130 & 42.3 \\
\hline Yes & 177 & 57.7 \\
\hline Total & 307 & 100.0 \\
\hline
\end{tabular}

EC: emergency contraception; IUD: intrauterine device. 


\section{Measurement model}

All measurement model coefficients were statistically significant. Confirmatory factor analysis of the 10 items that constituted the construct knowledge of EC showed that issues QA, QB, QD, QF, QH, QI and QJ had a factor loading greater than 0.40 (Table 2). However, we did not keep QC, QE e QG on the reduced model since the CFI value was more appropriate without these items. QB was the variable that presented the highest load (0.779) (Table 2).

\section{Structural model}

The fit model analysis showed satisfactory indices: chi-square $\mathrm{p}$-value ( $\mathrm{p}=0.003)$; CFI (0.938); TLI (0.911); RMSEA (0.049). In the structural equation model (Table 3 and Figure 2), the knowledge of EC (QA, QB, QD, QF, QH, QI, QJ) (SC = $0.129, \mathrm{p}=0.150$ ), the age of sexual initiation ( $\mathrm{SC}=$ $-0.052, \mathrm{p}=0.430$ ) and the type of school (SC = $-0.093, p=0.151$ ) did not show significant effects on the use of EC. Only the variable knowledge of someone who had already used EC showed a significant and direct effect on the use of EC. This means that for each variation of one standard deviation in the knowledge of someone who had already used EC, there was a significant increase of 0.379 standard deviation on the use of EC ( $p<$ 0.001 ), corresponding to a medium effect. For the same variable, the model using MLR estimator showed an OR of 5.93 (95\% confidence interval 95\%CI: 3.15-11.18). For the variable knowledge of EC, the OR was 1.17 and non-significant $(95 \% \mathrm{CI}$ : 0.95-1.44).

Other significant associations found were: age of sexual initiation ( $\mathrm{p}=0.032)$, type of school $(\mathrm{p}<0.001)$ and knowledge of someone who has used EC ( $p=0.007)$ on the knowledge of EC; and type of school on age of sexual initiation $(\mathrm{p}<$ 0.001 ). There were no significant indirect effects on the use of EC.

\section{Discussion}

More than half of the subsample of adolescents reported they had previously used EC at least once. This percentage is much higher than shown in other studies $25,26,27,28,29$. While it re veals a positive aspect of contraception behavior, since it appears the adolescents could access EC whenever they faced an unprotected sexual intercourse, it can also be seen as a marker of many failures and discontinuities in the use of regular contraceptive methods. A higher use of EC has no negative effects on regular contraception use 30 , therefore we assume that EC use is more related to discontinuities than to the non-use itself, as described elsewhere 13,31.

Table 2

Factor analysis of knowledge of emergency contraception. Brazil, 2011

\begin{tabular}{|c|c|c|c|c|}
\hline \multirow[t]{2}{*}{ Confirmatory factor analysis } & \multicolumn{2}{|c|}{ Complete model } & \multicolumn{2}{|c|}{ Reduced model } \\
\hline & $\lambda$ & p-value & $\lambda$ & p-value \\
\hline QA: EC should be used before intercourse & 0.663 & $<0.001$ & 0.663 & $<0.001$ \\
\hline QB: EC prevents STDs & 0.764 & $<0.001$ & 0.779 & $<0.001$ \\
\hline $\begin{array}{l}\text { QC: If vomiting occurs within } 2 \text { hours after ingestion of EC, the dose should be } \\
\text { repeated }\end{array}$ & 0.086 & 0.308 & & \\
\hline QD: EC is more effective than other contraceptives (such as condoms, pill, IUD) & 0.480 & $<0.001$ & 0.475 & $<0.001$ \\
\hline QE: EC is to be used within 5 days after unprotected intercourse & 0.189 & 0.019 & & \\
\hline QF: EC can be used once a month & 0.462 & $<0.001$ & 0.438 & $<0.001$ \\
\hline QG: EC is abortive & 0.333 & $<0.001$ & & \\
\hline $\mathrm{QH}$ : EC should be used only during fertile period & 0.676 & $<0.001$ & 0.665 & $<0.001$ \\
\hline Ql: EC replaces the regular oral pill & 0.762 & $<0.001$ & 0.756 & $<0.001$ \\
\hline QJ: When using EC, one is protected from getting pregnant until the next period & 0.611 & $<0.001$ & 0.630 & $<0.001$ \\
\hline RMSEA & 0.046 & & 0.069 & \\
\hline $\mathrm{CFI}$ & 0.952 & & 0.954 & \\
\hline TLI & 0.938 & & 0.930 & \\
\hline
\end{tabular}

CFI: Comparative Fit Index; EC: emergency contraception; IUD: intrauterine device; RMSEA: root mean square error of approximation;

STDs: sexually transmitted diseases; TLI: Tucker Lewis index. 
Standardized coefficients of the structural equation model for emergency contraception use among high school adolescents. Brazil, 2011.

\begin{tabular}{|c|c|c|c|c|c|}
\hline Effects & $\begin{array}{l}\text { Standardized } \\
\text { coefficient }\end{array}$ & $\begin{array}{l}\text { Standard } \\
\text { error }\end{array}$ & $\mathrm{p}$-value & OR & $95 \% \mathrm{Cl}$ \\
\hline \multicolumn{6}{|l|}{ Knowledge of EC by } \\
\hline QA: EC should be used before intercourse * & 0.673 & 0.087 & $<0.001$ & & \\
\hline QB: EC prevents STDs & 0.762 & 0.074 & $<0.001$ & & \\
\hline $\begin{array}{l}\text { QD: EC is more effective than other contraceptives } \\
\text { (such as condoms, pill, IUD) }\end{array}$ & 0.462 & 0.076 & $<0.001$ & & \\
\hline QF: EC can be used once a month & 0.439 & 0.076 & $<0.001$ & & \\
\hline QH: EC should be used only during fertile period & 0.676 & 0.067 & $<0.001$ & & \\
\hline QI: EC replaces the regular oral pill & 0.762 & 0.072 & $<0.001$ & & \\
\hline $\begin{array}{l}\text { QJ: When using EC, one is protected from getting } \\
\text { pregnant until the next period }\end{array}$ & 0.651 & 0.074 & $<0.001$ & & \\
\hline \multicolumn{6}{|l|}{ Knowledge of EC } \\
\hline Type of school & 0.282 & 0.055 & $<0.001$ & & \\
\hline Age of sexual initiation & 0.140 & 0.066 & 0.032 & & \\
\hline Knowledge of someone who had already used EC & 0.187 & 0.069 & 0.007 & & \\
\hline \multicolumn{6}{|l|}{ Age at sexual initiation } \\
\hline Type of school & 0.181 & 0.041 & $<0.001$ & & \\
\hline Knowledge of someone who had already used EC & 0.024 & 0.068 & 0.720 & & \\
\hline \multicolumn{6}{|l|}{ Use of EC } \\
\hline Knowledge of EC & 0.129 & 0.089 & 0.150 & 1.17 & $0.95-1.44$ \\
\hline Type of school & -0.093 & 0.065 & 0.151 & 0.64 & $0.35-1.18$ \\
\hline Age of sexual initiation & -0.052 & 0.066 & 0.430 & 0.93 & $0.78-1.11$ \\
\hline Knowledge of someone who had already used EC & 0.379 & 0.061 & $<0.001$ & 5.93 & $3.15-11.18$ \\
\hline
\end{tabular}

95\% Cl: 95\% confidence interval; EC: emergency contraception; IUD: intrauterine device. OR: odds ratio.

* Fixed parameter (variable with the largest factorial load).

With respect to the knowledge of EC, it is clear that the adolescents know little about its indications, mechanism of action and effectiveness. From the answers to the ten items that measured the knowledge around EC, we can observe they are mainly sure that EC is a method to be used after unprotected intercourse (QA) and it does not prevent STDs (QB). The adolescents mostly chose incorrect options for the other items. Studies also showed that adolescents generally lack sufficient knowledge about what EC is and its mechanism of action 28,32. We have not assessed if the poor knowledge around EC influences its correct use and that is clearly a gap in the full understanding of the relation between the knowledge of EC and its use. For instance, are the adolescents who think that EC should be used only during fertile periods more likely to not use it whenever indicated?

Nevertheless, the knowledge around EC did not show any significant direct or indirect effect on its use. Because EC knowledge had no statistical effect on EC use in our population, we conclude that high school adolescents are using the method regardless of their good or poor knowledge about it. The reason might be that they have the information they need, such as where to access the medication, if it worked for someone else in preventing a pregnancy, and even its side effects. Furthermore, the knowledge of someone who had used EC was significantly associated to EC use. Our assumption is that experience - both positive and negative - of EC use can be widely disseminated by peers, which contributes to broaden the dissemination and knowledge of EC among adolescents 33. Indeed, a British study emphasized that the peer group has a very important role in relation to EC use and access 33 . As the peers might have had the same experience of unprotected sexual relations and needed to use EC, they have recommendations to share without making judgments. In England, they even helped their peers to access EC by accompanying them to the health services. In that way, the author emphasizes that "it is not so much accurate contraceptive information they (adolescents) value, but insider knowledge" 33 (p. 685 ). Although we did not ask adolescents direct- 
Standardized coefficients of the structural equation model for emergency contraception (EC) use among adolescent high school students. Brazil, 2011.

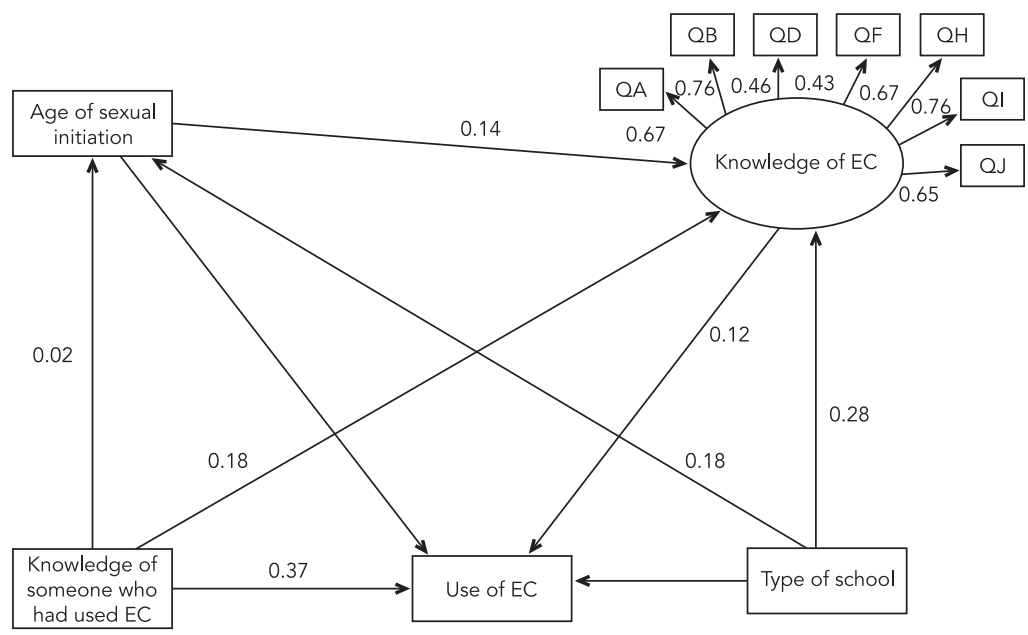

QA: EC should be used before intercourse; QB: EC prevents STDs; QD: EC is more effective tham other contraceptives (such as condoms, pill, IUD); QF: EC can be used once a month; $\mathrm{QH}$ : EC should be used only during fertile period; $\mathrm{QI}$ : EC replaces the regular oral pill; $\mathrm{QJ}$ : when using $\mathrm{EC}$, once is protected from getting pregnancy until the next period.

ly about their peers, we assume that the person (or persons) they knew that had already used EC was from their social network, most likely another adolescent, close enough to them that they felt confident to ask about and share experiences on sexual and contraceptive matters. Possibly, that is why knowing someone who had already used EC had a significant prominent role on its use. Although the use of EC, or any other contraceptive method, has been largely associated with knowledge about it, there remains strong evidence that it does not solely influence the use of EC among adolescents. Based on these findings, it is clear that adolescents' knowledge about EC needs to be expanded; however, the extent to which it affects EC use is still unknown.

Study limitations include information bias regarding sexual and contraceptive behavior, since the question on this subject can cause embarrassment around confidentiality of information provided. In this sense, some care has been taken: the questionnaires were anonymous, participation was voluntary and urns were placed in front of the classroom to deposit the completed questionnaires. We also cannot extrapolate the results to Brazil as a whole as our subsample is from a medium-sized city in the country. Moreover, we selected individuals from a broader study, which led us to a smaller subpopulation. On the one hand, we have selected only sexually experienced adolescents; on the other we could not have established this inclusion criterion $a$ priori due to ethical limitations. This is important because our sample size did not allow for stratification by gender, which is undoubtedly a limitation. However, studies have shown that boys report a similar frequency of EC use compared to girls ${ }^{12}$. If the determinants of EC use among male adolescents are the same among female ones, it is not clear so far.

This study's strengths are the way EC knowledge was measured - a latent variable composed of seven items - and the fact that students from both public and private high schools were included. Differences between public and private schools in Brazil reflect social disparities, as the family income exerts a direct influence on educational opportunities, and families with higher incomes tend to choose private schools, which present better performances in students' assessments 24 . Furthermore, the majority of private schools in Brazil usually deny participating in any kind of research with a focus on sexual matters, arguing that it could lead adolescents into early and unacceptable sexual behavior. 


\section{Contributors}

C. B. N. Chofakian and A. L. V. Borges contributed to study design, analysis and interpretation of the data and writing the article. A. P. S. Sato, G. P. Alencar, O. A. Santos and E. Fujimori contributed in data analysis, data interpretation and writing of the article.

\section{Acknowledgments}

This work was supported by the São Paulo Research Foundation (FAPESP process number 2010/14228-5).

\section{References}

1. World Health Organization. Emergency contraception. Fact sheet no. 244. http://www.who.int/ mediacentre/factsheets/fs244/en/ (accessed on 09/Nov/2014).

2. Berquó E, Garcia S, Lima L. Youth and reproduction: demograhic, behavioral and reproductive profiles in the PNDS-2006. Rev Saúde Pública 2012; 46:685-93.

3. Ali MM, Cleland J. Sexual and reproductive behavior among single women aged 15-24 in eight Latin American countries: a comparative analysis. Soc Sci Med 2005; 60:1175-85.
4. Falah-Hassani K, Kosunen E, Shiri R, Rimpelä A. Emergency contraception among Finnish adolescents: awareness, use and the effect of non-prescription status. BMJ 2007; 7:201-12.

5. Daniels K, Jones J, Abma J. Use of emergency contraception among women aged 15-44: United States, 2006-2010. NCHS Data Brief 2013; (112):1-8. 6. Walker DM, Torres DP, Gutierrez JP, Kendra MS, Flemming MD, Bertozzi SM. Emergency contraception use is correlated with increased condom use among adolescents: results from Mexico. J Adolesc Health 2004; 35:329-34. 
7. Ottesen S, Narring F, Renteria SC, Michaud PA. Emergency contraception among teenagers in Switzerland: a cross-sectional survey on the sexuality of 16- to 20-year-olds. J Adolesc Health 2002; 31:101-10.

8. Häggstrom-Nordin E, Tydén T. Swedish teenagers' attitudes toward the emergency contraceptive pill. J Adolesc Health 2001; 28:313-18.

9. Xu J, Cheng L. Awareness and usage of emergency contraception among teenagers seeking abortion: a Shanghai survey. Eur J Obstet Gynecol Reprod Biol 2008; 141:143-6.

10. Perpétuo IHO. Contracepção de emergência na adolescência e a PNDS 2006. In: Arilha M, Lapa TS, Pisaneschi TC, organizadores. Contracepção de emergência no Brasil e América Latina: dinâmicas políticas e direitos sexuais e reprodutivos. São Paulo: Oficina Editorial; 2010. p. 91-120.

11. Cameron ST, Gordon R, Glasier A. The effect on use of making emergency contraception available free of charge. Contraception 2012; 86:366-96.

12. López-Amorós M, Schiaffino A, Moncada A, Pérez G. Factores asociados al uso autodeclarado de la anticoncepción de emergencia en la población escolarizada de 14 a 18 años de edad. Gac Sanit 2010; 24:404-9.

13. Borges ALV, Fujimori E, Hoga LAK, Contin M. Práticas contraceptivas entre jovens universitários: 0 uso da anticoncepção de emergência. Cad Saúde Pública 2010; 26:816-26.

14. Sorensen MB, Pedersen BL, Nurnberg LE. Differences between users and non-users of emergency contraception after a recognized unprotected intercourse. Contraception 2000; 62:1-3.

15. Departamento de Ciência e Tecnologia, Secretaria da Ciência, Tecnologia e Insumos Estratégicos, Ministério da Saúde. PNDS 2006: Pesquisa Nacional de Demografia e Saúde da Criança e da Mulher: relatório. http://bvsms.saude.gov.br/bvs/pnds/ img/relatorio_final_PNDS2006_04julho2008.pdf (accessed on 15/Apr/2015).

16. Kline RB. Principles and practice of structural equation modeling. $3^{\text {rd }}$ Ed. New York: Guilford Press; 2010.

17. Wolf EJ, Harrington KM, Clark SL, Miller MW. Sample size requirements for structural equation models: an evaluation of power, bias, and solution propriety. Educ Psychol Meas 2013; 73:913-34.

18. Araújo MSP, Costa LOBF. Sexual behavior and emergency contraception among adolescents from public schools in Pernambuco State, Brazil. Cad Saúde Pública 2009; 25:551-62.

19. Chofakian CBN, Borges ALV, Fujimori E, Hoga LAK. Conhecimento sobre anticoncepção de emergência entre adolescentes do Ensino Médio de escolas públicas e privadas. Cad Saúde Pública 2014; 30:1525-36.
20. Rabe-Hesketh S, Skrondal A, Pickles A. Generalized multilevel structural equation modeling. Psychometrika 2004; 69:167-90.

21. Laros JA. O uso da análise fatorial: algumas diretrizes para pesquisadores. In: Pasquali L, organizador. Análise fatorial para pesquisadores. Brasília: LabPAM Saber e Tecologia; 2005. p. 163-84.

22. Hu L, Bentler PM. Cut off criteria for fit indexes in covariance structure analysis: conventional criteria versus new alternatives. Struct Equ Modeling 1999; 6:1-55.

23. Hooper D, Coughlan J, Mullen MR. Structural equation modelling: guidelines for determining model fit. Electronic Journal of Business Research Methods 2008; 6:53-60.

24. Costa LA, Arraes RO. Contrastes da política educacional brasileira entre escolas privadas e públicas. In: Hermanns K, Arraes RA, organizadores. Desigualdades e políticas regionais. Fortaleza: Fundação Konrad Adenauer; 2007. p. 137-64.

25. Sidebottom A, Harrison PA, Donna A, Finnegan K. The varied circumstances prompting requests for emergency contraception at school-based clinics. J Sch Health 2008; 78:258-63.

26. Costa KBS, Carvalho ACG, Santos KB, Mendes SHFM, Soares A. Contracepção de emergência entre adolescentes do Rio de Janeiro. Revista da Sogia-BR 2006; 7:3-6.

27. Fine LC, Mollen CJ. A pilot study to assess candidacy for emergency contraception and interest in sexual health education in a pediatric emergency department population. Pediatr Emer Care 2010; 26:413-16.

28. Ahern R, Frattarelli LA, Delto J, Kaneshiro B. Knowledge and awareness of emergency contraception in adolescentes. J Pediatr Adolesc Gynecol 2010; 23:273-8.

29. Miller LM. College student knowledge and attitudes toward emergency contraception. Contraception 2011; 83:68-73.

30. Meyer JL, Gold MA, Haggerty CL. Advance provision of emergency contraception among adolescent and young adult women: a systematic review of literature. J Pediatr Adolesc Gynecol 2011; 24:2-9.

31. Gaudineau A, Ehlinger V, Gabhainn SN, Vayssiere C, Arnaud C, Godeau E. Use of emergency contraceptive pill by 15 -year-old girls: results from the international Health Behaviour in School-aged Children (HBSC) study. BJOG 2010; 117:1197-204.

32. Nunes MT. Conhecimento e utilização da contracepção de emergência em alunas do ensino secundário em Guimarães. Revista Portuguesa de Medicina Geral e Familiar 2005; 21:247-56.

33. Fallon D. Accessing emergency contraception: the role of friends in the adolescent experience. Sociol Health Illn 2010; 32:677-94. 


\section{Resumo}

O objetivo do trabalho foi testar como o conhecimento da anticoncepção de emergência, na presença da idade de iniciação sexual, tipo de escola e conhecer alguém que já usou a anticoncepção de emergência, influencia no uso deste método. Estudo transversal realizado com uma amostra probabilística com estudantes de 15-19 anos, matriculados no Ensino Médio de escolas públicas e privadas em uma cidade de porte médio do Sudeste do Brasil $(n=307)$. Os dados foram coletados em 2011, por meio de um questionário autoadministrado. Modelo de equações estruturais foi usado para análise de dados. Considerando a idade de iniciação sexual e o tipo de escola, o conhecimento da anticoncepção de emergência não foi associado com o seu uso, no entanto, conhecer alguém que já tinha usado o método mostrou um efeito médio significativo no uso da anticoncepção de emergência. Parece que as conversas a respeito do uso da anticoncepção de emergência nas relações sociais, como o grupo de pares, têm maior influência sobre a utilização do método do que o próprio conhecimento, situação econômica ou experiência sexual.

Anticoncepção Pós-Coito; Saúde Sexual e Reprodutiva; Saúde do Adolescente

\section{Resumen}

El objetivo del estudio fue probar cómo el conocimiento sobre la anticoncepción de emergencia, durante la edad de iniciación sexual, tipo de escuela y conocer a alguien que ya usó métodos anticonceptivos de emergencia, influencia en el uso de este método. Se trata de un estudio transversal, realizado con una muestra probabilística con estudiantes de 15-19 años matriculados en Enseñanza Media de escuelas públicas y privadas en una ciudad mediana del sudeste de Brasil ( $n=307)$. Los datos se recogieron en 2011, a través de un cuestionario auto-administrado. Se usó un modelo de ecuaciones estructurales para el análisis de datos. Considerando la edad de iniciación sexual, y el tipo de escuela, el conocimiento de la anticoncepción de emergencia no fue asociado con su uso, no obstante, conocer a alguien que ya había usado el método mostró un efecto medio significativo en el uso de métodos anticonceptivos de emergencia. Parece que las conversaciones, respecto al uso de la anticoncepción de emergencia en las relaciones sociales, como el grupo de parejas, tiene mayor influencia sobre la utilización del método que el propio conocimiento, situación económica o experiencia sexual.

Anticoncepción Poscoital; Salud Sexual y Reproductiva; Salud del Adolescente 